\title{
Erratum to: Information Technology - New Generations
}

Shahram Latifi

\section{Erratum to:}

S. Latifi (ed.), Information Technology - New Generations, Advances in Intelligent Systems and Computing 738, https://doi.org/10.1007/978-3-319-77028-4

This book was inadvertently published without updating the following corrections:

\section{Chapter 30:}

The following Author's name was missing, this has been added now

"Leandro Guarino de Vasconcelos"

\section{Chapter 77:}

There was a mistake in the author affiliation in Chapter 77. The affiliation should read as below:

Vanel Lazcano

Núcleo de Matemáticas, Física y Estadística, Facultad de Ciencias, Universidad Mayor, Chile

\section{Chapter 85:}

The contributing Authors' names were wrongly presented as "Abd Rahman Al Asmar" and "Abd Al Rahem Jarrah". The correct names should read as below:

"Abdel Rahman Alasmar"

"Abdulraheem Aljarrah"

\footnotetext{
The updated online version of these chapters can be found under https://doi.org/10.1007/978-3-319-77028-4_30 https://doi.org/10.1007/978-3-319-77028-4_77 https://doi.org/10.1007/978-3-319-77028-4_85 https://doi.org/10.1007/978-3-319-77028-4
} 